\title{
Opinião
}

\section{Reflexão sobre a educação à distância no curso de graduação em fisioterapia}

\author{
Aline Mizusaki Imoto, Ft. D.Sc.*, Aline Teixeira Alves, M.Sc., Samira Mendonça de Almeida, Ft.***, \\ Débora Caetano de Souza Martins Guimarães**** \\ *Universidade Federal de Sáo Paulo - UNIFESP, **Doutoranda em Ciências da Saúde, Universidade de Brasilia - UNB, ***Espe- \\ cialista em Ortopedia e Esportes - Universidade Federal de Minas Gerais - UFMG, ${ }^{* * *}$ Mestranda do Programa de Pós-Graduação \\ em Enfermagem, Universidade de Brasilia - UNB
}

A inclusão da tecnologia no processo de educação tem provocado uma revolução no processo de ensino/aprendizagem. O acesso à Internet e o uso do computador possibilitam a rápida disseminação da informaçáo [1].

O advento de cursos de graduaçáo à distância possibilitou a inclusão de indivíduos que normalmente não teriam condições de frequentar aulas presenciais. A flexibilidade de horários, a não obrigatoriedade de frequência diária e a disponibilizaçáo ininterrupta de aulas e orientaçóes on line aumentam consideravelmente o número de pessoas que podem ser incluídas nesse processo de formação [2].

Com base em estudos existentes no Brasil que abordam a Educação à Distância (EAD) na área de saúde, em especial, a fisioterapia, o objetivo da presente reflexão é propor uma estratégia de EAD para os cursos de graduação em Fisioterapia.

A formação do fisioterapeuta, como em outras áreas da saúde, envolve o contato com o paciente, a prática manual e a vivência em ambientes de clínica ou hospitalar. Dessa forma, assim como a teoria, a prática é essencial durante a graduação em Fisioterapia.

Em um estudo realizado com docentes do curso de $\mathrm{Fi}$ sioterapia da Universidade Federal de Santa Maria (UFSM), observou-se que o Projeto Político Pedagógico do curso de Fisioterapia era orientado por diretrizes inovadoras e que havia a possibilidade de aplicar princípios andragógicos no processo ensino-aprendizagem a fim de adequar o método de ensino tradicional às novas demandas do currículo com o propósito de qualificar o ensino em Fisioterapia [3].

Entretanto, os cursos de graduação em Fisioterapia convivem com uma limitação no uso de tecnologias da informação que se restringe ao uso de computadores nas disciplinas básicas [3], na soluçáo de problemas administrativos e na comparação de sua utilizaçáo com o ensino tradicional [4]. Estudos mostram os benefícios das tecnologias de comunicação na área da saúde, como enfermagem [5], medicina [6] e odontologia [7]. Entretanto, na fisioterapia existem poucos relatos sobre o uso da EAD.

Segundo Martins [8], "há ainda certa resistência à metodologia a distância não só para o curso de Graduação em Fisioterapia, mas também para vários outros da área da saúde, por receio quanto à preservação da qualidade dos cursos". $\mathrm{O}$ mesmo defende também a aplicação de cursos semipresenciais, respeitando as especificidades de cada área, considerando que os momentos de aulas práticas em laboratórios deverão ser ministrados no modo presencial.

Berto [9] criou um material didático sobre ensino de fisioterapia respiratória que consistia em manobras de higiene brônquica e de reexpansão pulmonar e oxigenoterapia. $\mathrm{O}$ material foi disponibilizado na internet e o aprendizado dos alunos foi avaliado. As mídias utilizadas foram vídeos, fotos e uma apostila. Os alunos tiveram acesso ao material por 15 dias. Após esse período, os alunos melhoraram o conhecimento de forma estatisticamente significante. $\mathrm{O}$ autor da pesquisa citada sugere que as tecnologias de comunicação podem facilitar o aprendizado em fisioterapia respiratória.

Em um estudo realizado com docentes de Fisioterapia na região metropolitana de Belo Horizonte/MG, com o objetivo de analisar a percepção do professor acerca do uso da Informática Educacional (IE) no ensino da Fisioterapia, observou-se que $60 \%$ da amostra acreditava na melhora do ensino com 
o uso da IE. No entanto, $75 \%$ apontaram a não-capacitação profissional docente como o principal fator de dificuldade de disseminação do uso do computador [10].

A escolha das mídias a serem utilizadas em um curso a distância deve ser com base no público alvo e no conteúdo. Segundo Almeida [11], a falta de interação entre as pessoas é um dos principais fatores responsáveis pela desmotivação e desistência nos cursos à distância.

Como sugestấo de modelo de EAD para alunos de fisioterapia, sugere-se o uso do modelo de ensino-aprendizagem semipresencial (MEAS) citado por Kemczinski [1], visto a importância da teoria e da prática. O MEAS intercala aulas presenciais e virtuais. $\mathrm{O}$ ambiente virtual incentiva o aluno para resolução de problemas, estimula a pesquisa, aplica exercícios dirigidos, tira dúvidas, além de oportunizar a autoaprendizagem e uso de recursos para conversação em tempo real através de bate-papo (chat) e lista de discussão [1]. Um dos pontos mais interessantes da inserção da EAD no aprendizado do aluno, é que este se torna um elemento ativo no processo de aprendizagem, com maior iniciativa e comprometimento.

Em conclusão, é possível perceber que a implementação de recursos tecnológicos na educação é uma tendência real. Quanto ao curso de graduação em Fisioterapia, algumas disciplinas com conteúdo prático perderiam muito se fossem ministradas a distância. Porém, o que se pretende com esta reflexão é nada mais que aumentar o leque de possibilidades de educar e implementar instrumentos que possam inovar o conteúdo de forma que fiquem mais atrativos e interessantes para o educando.

\section{Referências}

1. Kemczinski A, Freitas MCD, Castro JE. A transposição do conteúdo de aulas presenciais para virtuais: uma experiência no ensino de graduaçáo. Universidade Federal de Santa Catarina: Laboratório de Sistemas de Apoio à Decisão; 2002. [citado 2011 Fev 6]. Disponível em URL: http://www.labsad.ufsc.br/wordpress

2. Anuário 2007 Associação Brasileira de Educação a Distância - ABED [online]. [citado 2009 Jan 15]. Disponível em URL: http://www.abed.com.br

3. Vogt MS. Os princípios andragógicos no contexto do processo ensino-aprendizagem em fisioterapia [Tese]. Brasília: Universidade de Brasília: Faculdade de Ciências da Saúde; 2007.

4. Kinney P, Keskula DR, Perry JF. The effect of a computer assisted instructional program on physical therapy students. J Allied Health 1997;26:57-61.

5. Thompson EC. Computer assisted instruction in curricula of physical therapist assistants. Phys Ther 1987;67:1237-9.

6. Cooper C, Taft LB, Thelen M. Examining the role of technology in learning: an evaluation of online clinical conferencing. J Prof Nurs 2004;20:160-6.

7. Brahler CJ, Quitadamo IJ, Johnson EC. Students critical thinking is enhanced by developing exercise prescriptions using on-line learning modules. Adv Physiol Educ 2002;26:210-21.

8. Rubens Martins. Educação Superior a Distância: questôes, tendências e políticas no âmbito do Ministério da Educação. Palestra. Revista Colabor@ Digital 2005: 3(9).

9. Berto CCO. Criação, implantação e avaliação de um recurso didático multimídia como suporte para o ensino presencial de fisioterapia respiratória [Dissertação]. São Paulo: Faculdade de Medicina da Universidade de São Paulo; 2006.

10. Tonani RL. A percepção do professor acerca do uso da Informática Educacional no Ensino de Fisioterapia. Belo Horizonte: Centro Federal de Educação Tecnológica de Minas Gerais; 2008.

11. Almeida MEB. Educação a distância na internet: abordagens e contribuiçóes dos ambientes digitais de aprendizagem. Educação e Pesquisa 2003:29(2);327-40. 